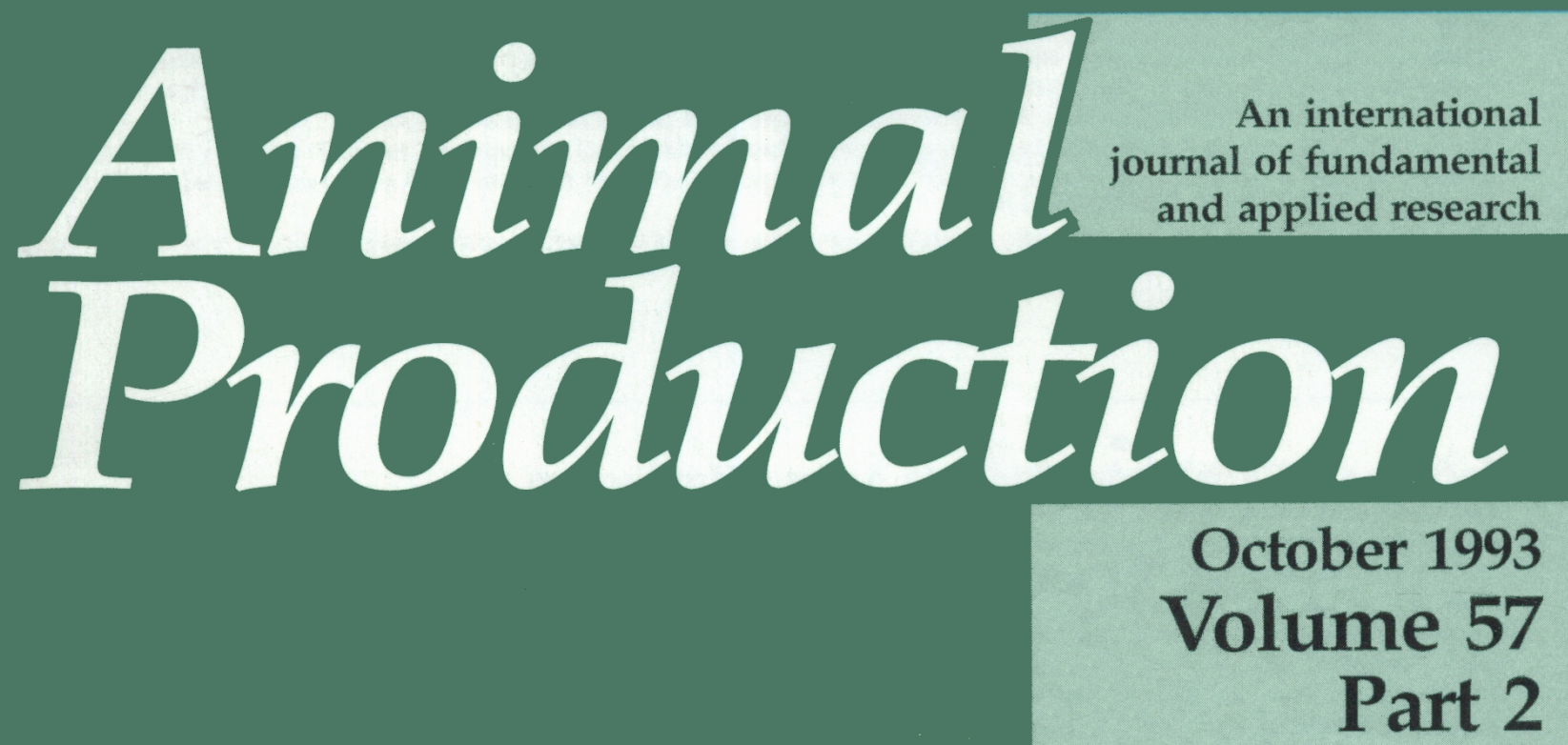

Published on behalf of the

British Society of Animal Production by $\mathbf{O}$ urrant

Member's copy 


\section{British Society of Animal Production}

The British Society of Animal Production was established in 1943 with the aim of providing the opportunity for those with an interest in animals and animal production to exchange views, ideas and information.

It has developed into an energetic and active society with over 1300 members from over 30 countries throughout the world. Today as ever the Society is the natural meeting point for all of those with an interest in animal production. Its membership is drawn from research, education, advisory work, commerce and practical livestock industry.

The Society's Journal is Animal Production which publishes fundamental and applied research and is a major scientific title of international repute. Original research from basic and applied sciences relevant to all aspects of animal production can be found in it.

The Society organizes a major scientific meeting once a year and occasional specialist meetings on key issues facing animal production. If you would like to join or receive further information about the Society contact: The Secretary, BSAP, PO Box 3 , Penicuik, Midlothian EH26 0RZ.

\section{Information for contributors to Animal Production}

Detailed notes for guidance in the preparation of manuscripts are printed in Volume 53: pages i-vii. A few general points are given below.

Animal Production, published six times a year in two volumes, prints reports in English, of original research in the basic and. applied sciences relevant to animal production. The investigations generally relate to the fields of animal breeding, nutrition, reproduction, health, behaviour, welfare, environment and housing and their interrelationships and pertain to biological processes and functions and to animal products. Work may be in the basic disciplines related to these fields or at a whole animal or whole systems level. The approach can be experimental or theoretical provided the work has been carried out in a systematic way and, in the former case, in a way which is ethically acceptable. Articles critically re-examining published information will also be considered. Papers presenting a detailed description of a technique or of equipment will be considered. Papers in a series are not accepted unless all are presented at the same time. Results of research work which do not warrant presentation as a full paper may be submitted for consideration as Notes. Notes are not intended for the publication of interim results. They must not exceed 2250 words or the equivalent inclusive of tables and illustrations. A proprietary product used as a source of material in experimental comparisons should be described by the appropriate chemical name, with the trade name given in parenthesis in the Material and methods section only, if this is seen as helpful to the readers. Authors should be careful in adhering to appropriate procedures when working with proprietary products and when reporting the results obtained.

Papers are published on the understanding that they have not been and, with the exception of authors' abstracts, will not be published elsewhere without the editors' written permission. Authors' abstracts can be reproduced if full acknowledgement of the source is made.

Manuscripts should be written in English and typed or printed on one side of the paper in double-line spacing with wide margins. Each page and the lines on each page should be numbered. Three copies, one of which must be the original, of the manuscript and illustrations should be sent to:

Dr T. L. J. Lawrence

Animal Production, Division of Animal Husbandry,

University of Liverpool Veterinary Field Station,

Neston, South Wirral, England L64 7TE.

Manuscripts are not returned with proofs: authors should therefore retain copies.

Units of measurement. The International System of Units (SI) should be used with the recommendations and modifications in Quantities, Units and Symbols, Royal Society, London, 1972 - reproduced in Proc.Nutr. Soc. 31: 239-247, 1972.

Symbols and abbreviations. Authors should consult the notes prepared for guidance.

Statistical significance. Levels of statistical significance must be clearly indicated. Treatment means should be given with standard errors or standard errors of differences. 
An international journal of fundamental and applied research

\section{Animal Production}

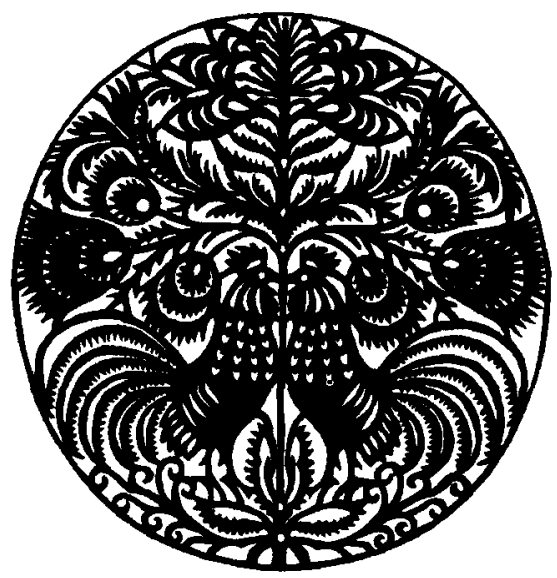

October 1993

Volume 57

Part 2 